\title{
Neuro and intraocular cysticercosis: A clinicopathological case report
}

\author{
This article was published in the following Dove Press journal: \\ Eye and Brain \\ 13 March 2010 \\ Number of times this article has been viewed
}

\author{
Dipankar Das' \\ Satyen Deka' \\ Saidul Islam² \\ Nilutparna Deuri' \\ Panna Deka' \\ Akshay Chandra Deka' \\ Hemalata Deka' \\ Sanjoy Kumar Buragohain' \\ Harsha Bhattacharjee' \\ 'Sri Sankaradeva Nethralaya, \\ Guwahati, Assam, India; ${ }^{2}$ Assam \\ Veterinary Science College, \\ Khanapara, Guwahati, Assam, India
}

Correspondence: Dipankar Das Associate Consultant, Department of Ocular Pathology, Uveitis and NeuroOphthalmology services, Sri Sankaradeva Nethralaya, Beltola, Guwahati - 781028, Assam, India

Tel +9936I 2228879

Fax +99 36I 2228878

Email dr_dasdipankar@yahoo.com

\begin{abstract}
Cysticercosis is one of the most common parasitic infestations in humans. Neurocysticercosis (NCC) is the commonest parasitosis of the central nervous system (CNS), endemic in developing countries and is also seen in developed nations with high rates of immigration from prevalent areas. Co-infection of ocular tissue is also significant and often ophthalmologists come across these lesions in their clinical practice. The mode of treatment in NCC and that of intraocular cysticercosis is somewhat different as far as antiparasitic treatment is concerned. This case report highlights the proper management of this parasitic infestation which involved both eye and brain.
\end{abstract}

Keywords: neurocysticercosis, endemic, scolex, corticosteroid

\section{Introduction}

Cysticercosis is a serious public health problem in several developing countries. ${ }^{1-3}$ It is estimated that 50 million people worldwide are infected with the taeniasis/cysticercosis complex and 50,000 die from cysticercosis annually. ${ }^{2-4}$ Most infected individuals are aged between 20-50 years and debilitation from cysticercosis represents an all-around financial blow, with considerable human suffering. Human and animal cysticercosis cause a loss of more than US\$3-4 billion annually, which are created by measures for control, medical intervention, and lost production. . $^{3,4}$

Humans are definitive hosts and pigs are the intermediate host for Taenia solium. .,3,5,6 $^{-1}$ In cysticercosis, humans become the intermediate host by ingesting the eggs of T. solium from contaminated food and water. After entering the intestinal wall, the embryo invades the blood stream and can lodge in various organs such as the central nervous system (CNS), eye, skeletal muscles, and subcutaneous tissue. ${ }^{5,6}$ The ocular manifestations can be destructive because the cysticercus lesion gradually increases in size, leading to blindness in 3 to 5 years. The death of the parasite causes a noticeable release of toxic yield, leading to intense inflammatory reactions and eye damage. ${ }^{6}$ Initial medical treatment of intraocular cysticercosis with antihelminthic drugs like albendazole or praziquantel is not known to be remedial. Early surgical removal of the parasite is the treatment of choice. ${ }^{5,6}$ We present a case of a young lady with intraocular cysticercosis with co-infected CNS.

\section{Case report}

A 29-year-old female presented to a tertiary institute of northeast India in January 2009 with complaints of seeing floaters and black spots in her left eye (OS) for past 20 days. She was referred from elsewhere with exudative retinal detachment and vitritis in 
the OS. She had a past history of convulsion in October 2008 and was put on an antiepileptic, carbamazepine. She was nondiabetic and nonhypertensive. She was non vegetarian and had consumed pork previously.

On examination, her visual acuity was 20/20, N6 in the right eye (OD) and 20/20-3, N10 in the OS. Anterior segment in both eyes were unremarkable. Vitreous reaction in the OS was $2^{+}$cells. Fundus examination of the OS revealed a colloid cyst of $4.5 \times 5.5$ disc diameter in the inferior temporal quadrant of the retina (Figure 1). There was associated retinal detachment in the lower half of the retina. B-scan ultrasound in the OS showed one cystic lesion, having a spherical curved echo corresponding to the cyst wall located in the

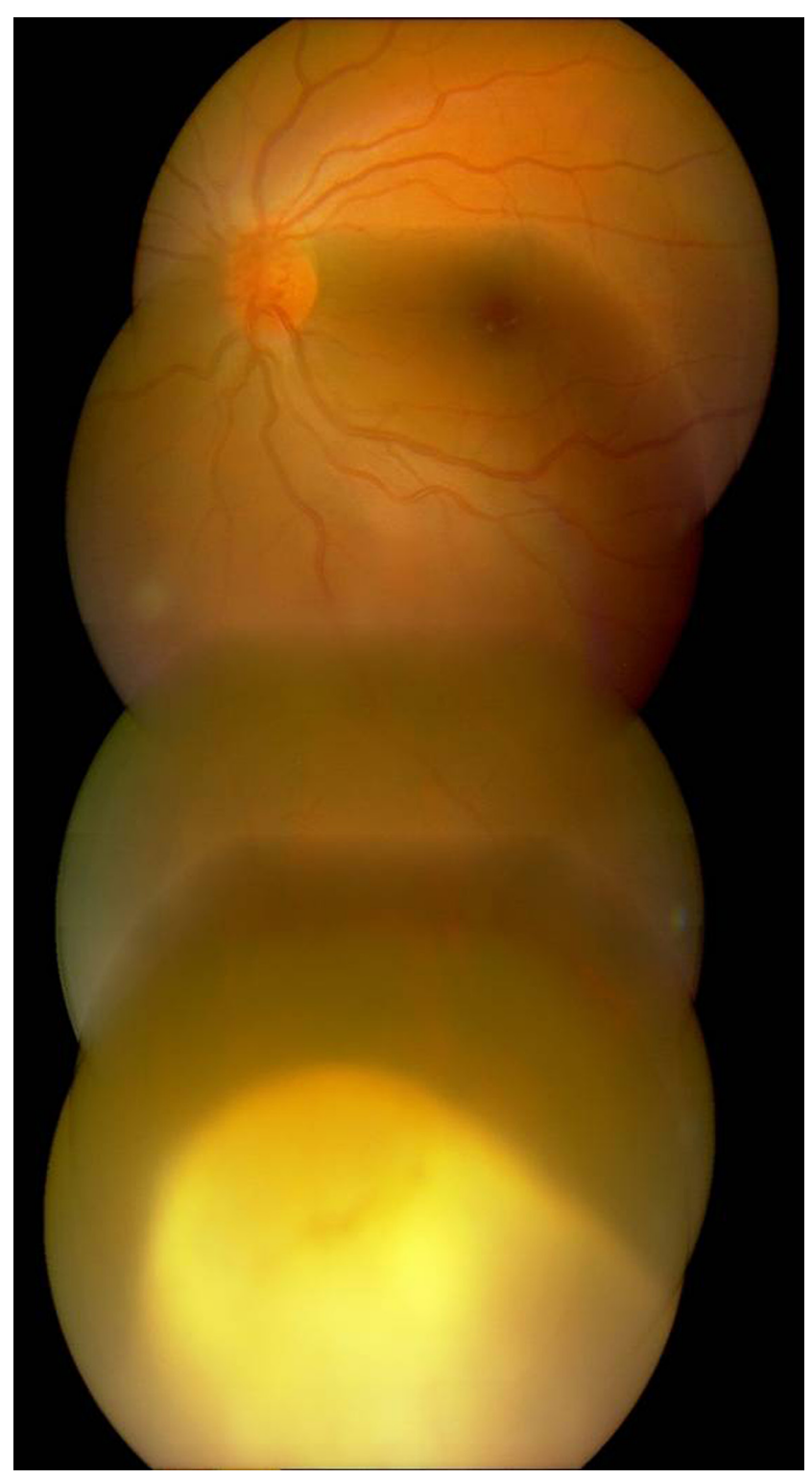

Figure I Fundus photo of the left eye revealed a colloid cyst of $4.5 \times 5.5$ disc diameter in the inferior temporal quadrant of the retina. inferotemporal retina with high reflective encircling spot scolex. An A-scan ultrasound demonstrated two high amplitude echoes corresponding to the cyst wall; a high reflective echo was seen when the beam passed from side to side of the scolex in real mode. Vitreous echoes were also seen (Figure 2). Magnetic resonance imaging (MRI) diagnosis showed multiple small coin-shaped degenerative lesions in the both cerebral hemispheres with focal edema (Figure 3). The patient was diagnosed with neurocysticercosis with an intraocular cysticercus cyst in the OS. Routine blood examination showed a high eosinophil count. Pars plana vitrectomy plus intraocular cyst removal with fluid gas exchange and an endolaser and silicone oil injection was done. Postoperative vision in OS was 20/30, N8, and the patient is regularly followed up. A course of oral albendazole (400 mg twice daily for six weeks) and steroid (1 mg/kg body weight in tapering dose for six weeks) was prescribed. The cyst was dissected out of the retina and was submitted to pathology laboratory in $10 \%$ formalin. After overnight fixation, the cyst became much more transparent. A parasitologist examined the cyst and found it to be in toto globular, transparent, and thin walled, with a small eccentrically located white area representing the scolex inside it. A gross photograph was taken and the cyst was measured (Figure 4). A histopathological section in hematoxylin and eosin stain showed trilaminated corrugated cell wall structures with well defined protoscolex (Figure 5a) and adjoining suckers and hooklets consistent of cystcercosis (Figure 5b).

\section{Discussion}

Human cysticercosis is ubiquitous worldwide ${ }^{1-3,5-8}$ including northeast India where consumption of semi- or improperly cooked pork, contaminated salad, and inadequate hygiene

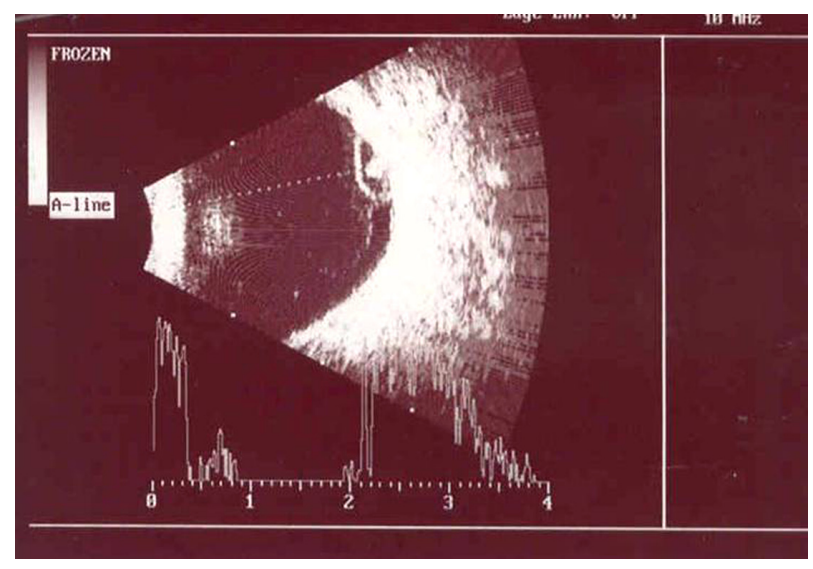

Figure 2 B-scan ultrasound in the left eye showed one cystic lesion with high reflective spot (scolex). 


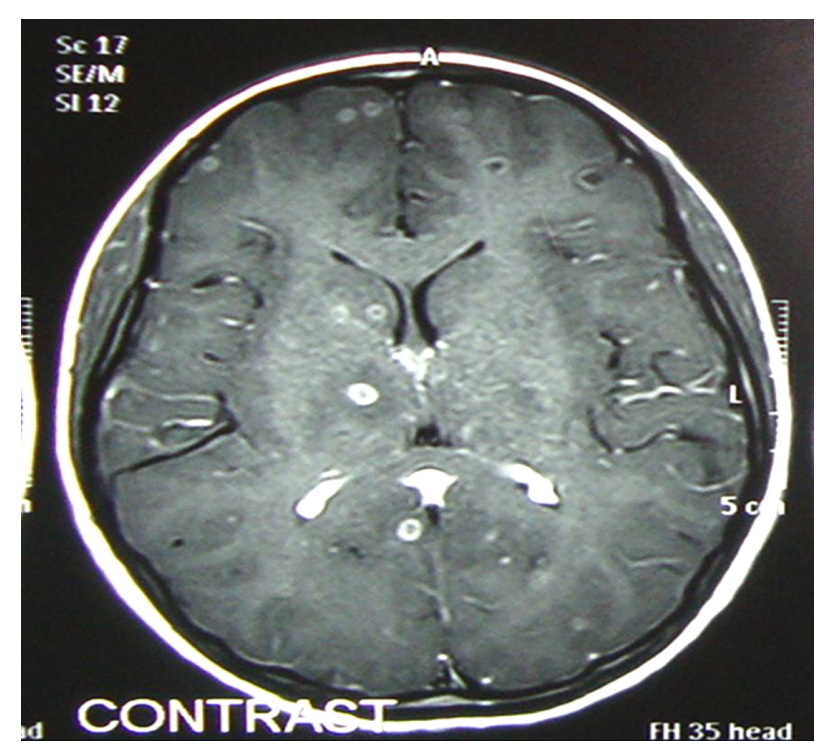

Figure 3 MRI scan of brain with contrast showed multiple small coin-shaped degenerating lesions in the cerebral hemispheres.

Abbreviation: MRI, magnetic resonance imaging.

are all possible causes of taeniasis and thereby can cause autoinfection. ${ }^{2,3}$ Food habits, poor hygiene, autoinfection, or traveling patterns may be responsible for their distribution. ${ }^{1-3}$ Clinical presentations of cysticercosis in human may involve the CNS, eye, or other viscera. ${ }^{5}$ Ocular involvements include cysts in eyelids, extraocular muscles, orbit, conjunctiva, anterior chamber, uvea, retina-vitreous, and optic nerve., ${ }^{2,3,5,6}$ Although there are various reports of isolated ocular and intraocular cysticercosis in the literature, there are few reports of cysticercosis involving the eye and brain (Table 1).

Our patient was a young lady who had a complaint in the left eye and was diagnosed with inferior exudative retinal detachment with subretinal cyst in the left eye. Prior to

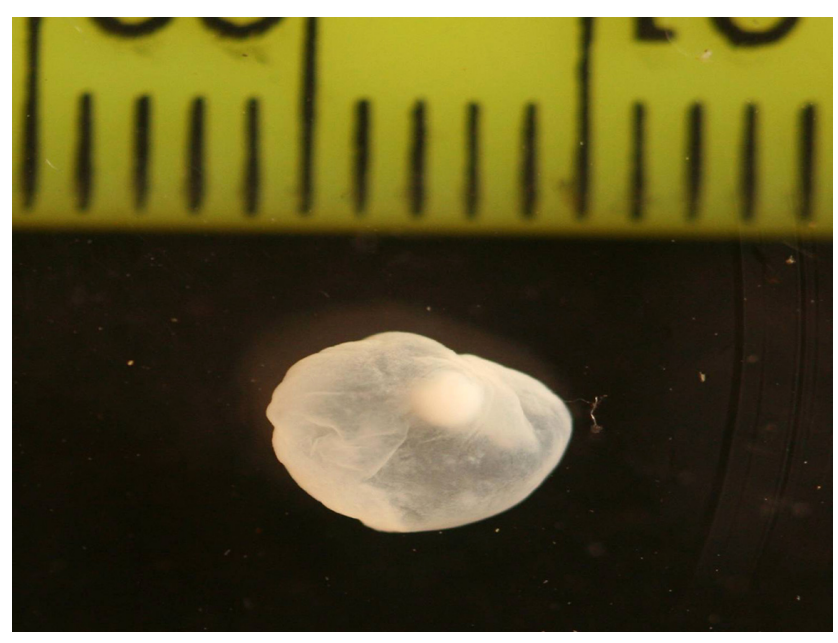

Figure 4 Gross photograph of the cysticercus cyst with scolex inside.
A)

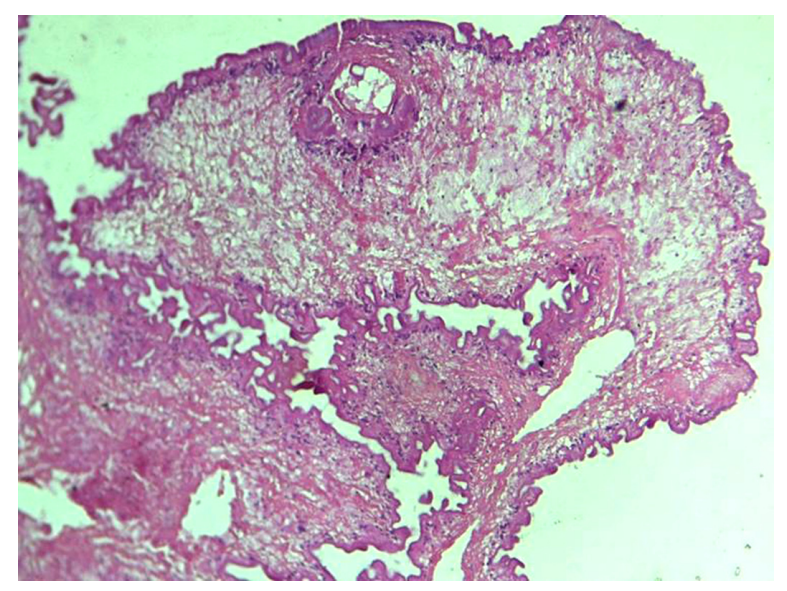

B)

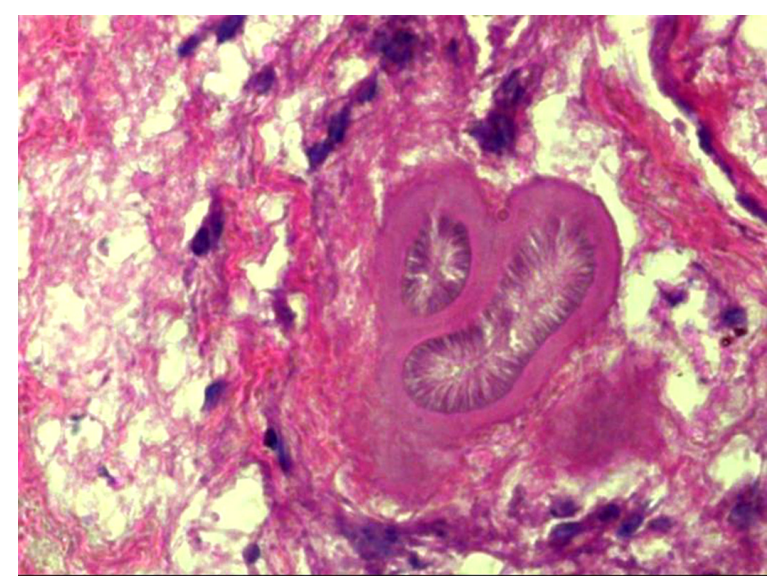

Figure 5 A) Photomicrograph $(\times 200)$ in hematoxylin and eosin stain showed trilaminated corrugated cell wall structures with well defined protoscolex. B) Photomicrograph $(\times 400)$ showed adjoining suckers in cysticercosis.

diagnosis, she had a history of convulsion and headache, which may have been be due to the parasite's involvement in the CNS. After removal of the intraocular cysticercus cyst, she was given a course of oral albendazole and steroid.

The intraocular cysticerci are removed either through an external sclerotomy with choroidal incision or via pars plana vitrectomy. ${ }^{6}$ Trans-scleral approaches are used for

Table I Neurocysticercosis with intraocular involvement

\begin{tabular}{lllll}
\hline SI No & Author & Reference & No of cases & Location \\
\hline I & Chadha & 13 & I & $\begin{array}{l}\text { Intravitreal } \\
\text { cysticercosis with } \\
\text { exudative RD } \\
\text { Ocular- } \\
\text { tuberculosis, } \\
\text { acquired } \\
\text { cysticercosis of the } \\
\text { eye and brain } \\
\text { Vertical dyplopia } \\
\text { and nystagmus }\end{array}$ \\
\hline & Rani & 14 & I & \\
& Jethani & 15 & 2 &
\end{tabular}

Abbreviation: RD, retinal detachment. 
subretinal cyst positioned anterior to the equator. The pars plana vitrectomy or transvitreal approach is used for intravitreal cyst and subretinal cyst located posterior to the equator. Vitreous cysts are more common than retinal or subretinal cysts and the inferotemporal subretinal cyst is the most commonly affected quadrant in the retina. ${ }^{6}$ The parasite may pierce the retina via choroidal circulation; the large choroidal vessels have a larger flow rate and subsequently the parasite migrates to subretinal space and then into the vitreous cavity. The passage of the endoparasite may incite inflammation and can even result in the formation of a chorioretinal scar. ${ }^{6}$ The cyst, in gross examination, was very typical with a shining eccentric scolex. Histopathological examination of the parasite showed the scolex and suckers. During follow-up, our patient maintained good visual acuity. Convulsive episodes were reduced during that time. The genesis of convulsion in a patient with neurocysticercosis may be due to inflammation, cerebral tissue gliosis, and preference of the cyst to travel to the cerebral hemisphere in general and frontal and temporal lobes in particular. ${ }^{4,6}$ Albendazole and praziquantel are the principal antiparasitic drugs used to treat neurocysticercosis. ${ }^{1,5,6,9}$ Numerous trials showed both these drugs reduce the number of cyst and frequency of seizures. ${ }^{9}$ Chronic epilepsy is usually associated with calcified granuloma. Cysts that are active or undergoing degeneration (colloidal cysts) are the most epileptogenic. ${ }^{9-12}$ If there are both intraocular and CNS cysticercus cysts, then the complete intraocular cyst must be removed surgically first, followed by antiparasitic medication and with corticosteroids. We do not want to kill the intraocular live parasite initially because it could induce severe intraocular reactions and thereby cause eventual blindness.

Combined intravitreal surgery by removing the subretinal cysticercus cyst and subsequent medical treatment for CNS parasitosis was safe and effective.

\section{Disclosures}

The authors report no conflicts of interest in this work.

\section{References}

1. Bern C, Gracia HH, Evans C, et al. Magnitude of the disease burden from neurocysticercosis in a developing country. Clin Infect Dis. 1999; 9:1203-1209.

2. Centers for Disease Control and Prevention. Recommendations of International Task Force for Disease Eradication (ITFDE). $M M W R$ Recomm Rep. 1993;42(RR-16):1-38.

3. Hoberg EP. Taenia tapeworms: their biology, evolution and socioeconomic significance. Microbes Infect. 2002;4:859-866.

4. Santos R, Chavarria M, Aguirre AE. Failure of medical treatment in two cases of intraocular cysticercosis. Am J Ophthalmol. 1984;97:249-250.

5. Sharma T, Sinha S, Shah N, et al. Intraocular cysticercosis: Clinical characteristic and visual outcome after vitreoretinal surgery Ophthalmology. 2003;110:996-1004.

6. Gemolotto G. A contribution to surgical treatment of intraocular cysticercosis. Arch Ophthalmol. 1955; 59:365-368.

7. Segal P, Mrzygold S, Smoloaz-Dudarewicz J. Subretinal cysticercosis in the macular region. Am J Ophthalmol. 1964;57:655-664.

8. Del Brutto OH, Sotelo J, Roman GC. Therapy of neurocysticercosis: a reappraisal. Clin Infect Dis. 1993;17:730-735.

9. Steinmetz RL, Masket S, Sidikaro Y. The successful removal of subretinal cysticercus by pars plana Vitrectomy. Retina. 1989;9:276-280.

10. Carpio A, Hauser A. Prognosis for seizure recurrence in patients with newly diagnosed neurocysticercosis. Neurology. 2002;59:1730-1734.

11. Carpio A, Kelvin EA, Bagiella E, et al. Effects of albendazole treatment on neurocysticercosis: a randomised controlled trial. J Neurol Neurosurg Psychiatry. 2008;79:1050-1055.

12. Garcia HH, Pretell EJ, Gilman RH, et al. A trial of antiparasitic treatment to reduce the rate of seizures due to cerebral cysticercosis. $N$ Engl J Med. 2004;350:249-258.

13. Chadha V, Pandey PK, Chauhan D, Das S. Simultaneous intraocular and bilateral extraocular muscle involvement in a case of disseminated cysticercosis. Int Ophthalmol. 2005;26(1-2):35-37.

14. Rani A, Pushker N, Kulkarni A, Rajpal Balasubramanya R, Bajaj MS. Simultaneous ocular and systemic cysticercosis and tuberculosis. Infection. 2006;34:169-172.

15. Jethani J, Vijayalakshmi P, Kumar M. Atypical ophthalmological presentation of neurocysticercosis in two children. JAAPOS. 2007;11(5): 495-496.
Eye and Brain

\section{Publish your work in this journal}

Eye and Brain is an international, peer-reviewed, open access journal focusing on clinical and experimental research in the field of neuroophthalmology. All aspects of patient care are addressed within the journal as well as basic research. Papers covering original research, basic science, clinical and epidemiological studies, reviews and evaluations,

Submit your manuscript here: http://www.dovepress.com/eye-and-brain-journal

\section{Dovepress}

guidelines, expert opinion and commentary, case reports and extended reports are welcome. The manuscript management system is completely online and includes a very quick and fair peer-review system, which is all easy to use. Visit http://www.dovepress.com/testimonials.php to read real quotes from published authors. 